\title{
NOTICE TO CONTRIBUTORS
}

Papers for consideration should be addressed to The Editor, The Aeronautical Quarterly, 4 Hamilton Place, London, W.1.

Papers must be as short as possible, twenty foolscap pages being considered a maximum. Those written as internal reports, i.e. with full descriptions and complete results of work, must be re-written concisely.

Manuscripts should be read critically by, say, a colleague before submission, in order to avoid small errors, which might otherwise prolong the refereeing process.

\section{PRESENTATION}

Papers submitted should comply with the following points:

1. They must be typewritten with double spacing.

2. The title must be short-with a sub-title if necessary.

3. A summary of not more than 250-300 words is essential.

4. Routine mathematics should be omitted or given in an Appendix and only necessary equations should be included in the text.

5. All symbols used in the text and figures, whether standard or not, must be listed in a Notation and the following points observed:

(a) The letter $l$ must be distinguished from the numeral 1 and the letter $O$ from the zero 0 .

(b) Greek letters should be clearly written in ink and should also be indicated, particular attention being paid to the use of alpha and $a$, kappa and $k$, mu and $u$, nu and $v$, eta and $n$.

(c) The use of dots, bars, and so on, over symbols, or the use of dots as multiplication signs and bars for brackets should be avoided as far as possible.

(d) Suffixes and indices must be clearly indicated and complicated suffixes avoided.

6. References should be given in the form:

Howell, W. T. Stability of Multi-Stage Axial Flow Compressors. Aeronautical Quarterly, Vol. XV, p. 328, November 1964.

7. Illustrations, which should be reduced to a minimum, may be presented in any of the following forms:

(a) As unlettered tracings for the Society's draughtsman to letter with standard stencils.

(b) Clear diagrams or sketches for complete redrawing at the Society.

(c) Clear black and white glossy photographs of not less than half-plate size.

\section{CONDITIONS OF PUBLICATION}

1. An author must obtain consent, where necessary, to use any material in his paper which is copyright or the property of any other person or his employers.

2. The copyright of every paper printed in The Aeronautical Quarterly is the property of The Royal Aeronautical Society. Permission to reprint or to use any paper will not be refused unreasonably.

\section{REPRINTS}

1. Authors will be entitled to six copies of The Aeronautical Quarterly in which their paper appears. This number will be shared by joint authors.

2. Authors can order any number of reprints and estimates are available. Orders must be received before publication of the paper.

The Aeronautical Quarterly is published at the Offices of The Royal Aeronautical Society, 4 Hamilton Place, London, W.1, at 17s. 6d. net for a single number to non-members and 8s. 6d. net for a single number to members of The Royal Aeronautical Society. None of the papers must be taken as expressing the opinion of the Council of The Royal Aeronautical Society unless such is definitely stated to be the case

Telephone: Grosvenor 3515. Cables: Didaskalos, London, W.1. 


\section{THE AERONAUTICAL QUARTERLY}

It is the aim of The Aeronautical Quarterly to attract not only original papers contributing to aeronautical science and engineering, and papers developing new or improved methods of analysis and experimental techniques, but also papers on allied sciences which have a bearing on aeronautical problems. The Aeronautical Quarterly is open to authors of any nationality and is not restricted to members of the Society. The time taken to publish a paper often depends on its length and short papers, of not more than 2000 words, can be published more quickly than longer ones.

\section{VOLUME XVII}

Volume XVII of The Aeronautical Quarterly is published in February, May, August and November 1966.

In February 1967 the prices of the Aeronautical Quarterly will be raised slightly to take into account the rise in the cost of postage and packing. The new prices are as follows:

\section{To Members of the Society}

$$
\text { f s. d. }
$$

\section{Per Part}

Subscription (4 parts)

$$
\begin{array}{lll}
9 & 6 & (\$ 1.50)
\end{array}
$$$$
\begin{array}{llll}
1 & 18 & 0 & (\$ 5.50)
\end{array}
$$

To Non-Members

f s. d.

$$
\text { 1. } 18 \quad 6
$$$$
314 \quad 0 \quad(\$ 10.30)
$$

Papers to be published in future issues include:

L. C. Squire-Calculated pressure distributions and shock shapes on thick conical wings at high supersonic speeds.

M. J. Goodyer-Roll control techniques on magnetic suspension systems.

T. Wah-Buckling of longitudinally stiffened plates.

M. P. Escudier, W. B. Nicoll, D. B. Spalding and J. H. Whitelaw-Decay of a velocity maximum in a turbulent boundary layer.

L. B. Jones-Lower bounds for sonic bangs.

L. J. S. Bradbury-Simple expressions for the spread of turbulent jets.

N. A. Cumpsty and M. R. Head-The calculation of three-dimensional turbulent boundary layers.

M. Zamir and A. D. Young -Similar and asymptotic solutions of the incompressible laminar boundary layer equations with suction.

G. A. O. Davies-Plate-reinforced holes.

PRINTED BY THE LEWES PRESS WIGHTMAN \& CO. LTD., LEWES, SUSSEX, ENGLAND, AND PUBLISHED BY THE ROYAL AERONAUTICAL SOCIETY, 4 HAMILTON PLACE, LONDON W.1, ENGLAND. 